\title{
MicroRNA-27a functions as a tumor suppressor in renal cell carcinoma by targeting epidermal growth factor receptor
}

\author{
YUEYAN LI，JIE LI，XIAOLEI SUN，JIACUN CHEN，XIAOQING SUN，JUNNIAN ZHENG and RENFU CHEN
}

\author{
Department of Urology, The Affiliated Hospital of Xuzhou Medical College, Xuzhou, Jiangsu 221002, P.R. China
}

Received February 18, 2015; Accepted January 13, 2016

DOI: $10.3892 / \mathrm{ol} .2016 .4500$

\begin{abstract}
Numerous studies have suggested that microRNAs (miRNAs) are vital in the development of various types of human cancers, including renal cell carcinoma (RCC), and the regulation of tumor progression and invasion. However, the effect of miRNA-27a (miR-27a) on the tumorigenesis of $\mathrm{RCC}$ is unclear. The aim of the present study was to investigate the function of miR-27a and identify its possible target genes in RCC cells. In the present study, cell proliferation, migration and invasion and the percentage of apoptotic cells were detected by methylthiazol tetrazolium assays, Annexin V analysis, wound-healing assays and Transwell invasion assays. Western blot analysis was performed to validate the protein expression level and assess whether the epidermal growth factor receptor (EGFR) was a target gene of miR-27a. A tumor xenograft animal model was used to detect the role of miR-27a on RCC cell growth in vivo. The present study demonstrated that miR-27a significantly suppressed human RCC 786-O cell proliferation and induced cell apoptosis. Restoration of miR-27 also resulted in 786-O cell migration and invasion inhibition. Furthermore, upregulated miR-27a attenuated RCC tumor growth in the tumor xenograft animal model. The present results suggested that miR-27a functions as a tumor suppressor in RCC. The western blot analysis assay revealed that EGFR was a novel target of miR-27a. The growth suppression of RCC cells was attributed partly to the downregulation of the cell cycle by ERFR inhibition. The present findings may aid in the understanding of the molecular mechanism of miR-27a in the tumorigenesis of RCC, and may provide novel diagnostic and therapeutic options for RCC.
\end{abstract}

\section{Introduction}

Among urological tumors, renal cell carcinoma (RCC) is the third leading cause of mortality (1). Worldwide,

Correspondence to: Professor Renfu Chen, Department of Urology, The Affiliated Hospital of Xuzhou Medical College, 99 Huaihai Road West, Xuzhou, Jiangsu 221002, P.R. China

E-mail: renfu_xzmu1963@163.com

Key words: microRNA, RCC, EGFR, proliferation $\sim 102,000$ individuals succumb to kidney cancer annually (2) and RCC accounts for 2-3\% of adult kidney malignancies (3). Surgical resection remains the definitive treatment for RCC, but $20-40 \%$ of patients may relapse following nephrectomy (4-6). The 5-year survival rate of patients with advanced RCC is extremely poor (5-10\%), due to recurrence or distant metastasis $(7,8)$. RCC is resistant to radiotherapy and chemotherapy (9). Targeted therapies, including sorafenib, sunitinib and the anti-angiogenic multi-tyrosine kinase inhibitors everolimus and temsirolimus, have been developed and widely used as first and second-line treatments; however, their impact on the survival rates of patients remains limited (10-12). The molecular mechanisms of recurrence, metastasis and drug resistance of RCC are not yet known. Therefore, an increased understanding of the molecular pathways of the progression of $\mathrm{RCC}$ is urgently required.

MicroRNAs (miRNAs) are endogenous, conserved, small non-coding RNA molecules (19-25 bp long) that regulate gene expression at the post-transcriptional level by binding to the partial sequence homology of the 3'-untranslated region of target messenger (m)RNA, which causes translation inhibition or mRNA degradation (13). It is known that miRNAs control a variety of key cellular processes, including the cell cycle and cell proliferation, differentiation and tumorigenesis (14). Previous studies have demonstrated that miRNAs are aberrantly expressed in various human cancers $(15,16)$, including RCC $(9,17)$. miRNAs are also vital in the initiation, development and metastasis of cancers (18). Additionally, miRNAs may function as oncogenes or tumor suppressor genes by specifically regulating target gene expression (19).

Various studies have evaluated the role of miRNAs in RCC. Yamasaki et al demonstrated that tumor suppressive miRNA-138 (miR-138) contributes to cell migration and invasion in RCC (20) and miRNA-218 significantly inhibits RCC cell proliferation, migration and invasion (21). Su et al revealed that let-7d may suppress $\mathrm{RCC}$ growth, metastasis and tumor macrophage infiltration by targeting COL3A1 and chemokine ligand-7 (22). A study by Chen et al demonstrated that miRNA-129-3p attenuates cell migration and invasion of RCC by downregulating multiple metastasis-associated genes, and may also act as a diagnostic and prognostic biomarker for RCC (23). Wu et al revealed that miRNA-133b was downregulated in RCC cell lines and inhibited cell proliferation, migration and invasion of RCC cells (24). These previous studies illustrate that tumor-associated miRNAs mediate 
cancer molecular pathways and may provide insights into the potential mechanisms of RCC oncogenesis and metastasis.

The miRNA-27 (miR-27) family consists of miR-27a and miR-27b, which are transcribed from different chromosomes and differ by one nucleotide at the $3^{\prime}$ end. miR-27a is located on chromosome 19 (25). miR-27a is altered in several types of cancer, including colon cancer (26), breast cancer (27), osteosarcoma (28) and gastric adenocarcinoma (29), to become an oncogene or a tumor suppressor. A study by Shi et al demonstrated that a genetic variant in the pre-miR-27a rs895819 is associated with a reduced RCC risk in a Chinese population (30). However, the effects of miR-27a on RCC have not yet been clearly elucidated. The present study evaluated the effect of miR-27a on the human RCC 786-O cell line and a RCC xenograft mouse model, and aimed to identify the possible mechanism through which this effect is achieved.

\section{Materials and methods}

Cell culture. The human RCC 786-O cell line was purchased from the Institute of Biochemistry and Cell Biology (Shanghai, China). The 786-O cells were grown in Invitrogen high-glucose Dulbecco's modified Eagle's medium (DMEM; Thermo Fisher Scientific, Inc., Waltham, MA, USA) supplemented with Gibco $10 \%$ fetal calf serum (FCS; Thermo Fisher Scientific, Inc.) and incubated at $37^{\circ} \mathrm{C}$ in a humidified atmosphere containing $5 \%$ $\mathrm{CO}_{2}$. The cells were regularly passaged to maintain exponential growth.

Cell transfection. A miR-27a precursor and miR-27a mimics (negative control) were purchased from Shanghai GenePharma Co., Ltd. (Shanghai, China). Cells at 70-80\% confluency were transfected with miR-27a or miR-27a mimics using Invitrogen Lipofectamine ${ }^{\circledR} 2000$ (Thermo Fisher Scientific, Inc.) according to the manufacturer's protocol. The cells were harvested and assayed at various time points following transfection. Each experiment was repeated three times.

Methylthiazol tetrazolium (MTT) assay. The proliferative capacity of the cells was evaluated using an MTT assay. Briefly, 786-O cells were seeded in Costar 96-well plates (Corning Inc., Corning, NY, USA) at a density of $4 \times 10^{3}$ cells/well and were then transfected with an miR-27a expression vector or miR-27a control (empty vector). Subsequent to 24 and $48 \mathrm{~h}$ of culture, $20 \mu \mathrm{l}$ MTT reagent (Sigma-Aldrich Chemie Gmbh, Munich, Germany) was added to each well and the cells were incubated for an additional $4 \mathrm{~h}$ at $37^{\circ} \mathrm{C}$. Optical density was assessed by measuring the absorbance at $490 \mathrm{~nm}$ with a microtiter plate reader (Model 680; Bio-Rad Laboratories, Inc., Hercules, CA, USA). Each experiment contained three replicates and was repeated at least twice. The data were expressed as the mean \pm standard deviation (SD).

Analysis of apoptotic cells. In total, $24 \mathrm{~h}$ subsequent to transfection, the cells were collected and washed twice with 1X phosphate-buffered saline (PBS; Sangon Biotech Co., Ltd., Shanghai, China) and stained using an Annexin V-fluorescein isothiocyanate (FITC) propidium iodide (PI) Detection kit (Nanjing KeyGen Biotechnology Co., Ltd., Nanjing, Jiangsu, China), following the manufacturer's protocol. Annexin V has a high affinity for phosphatidylserine, which is exposed on the cell surface of apoptotic cells (31). Early apoptotic cells that bind Annexin V-FITC exhibit green staining in the plasma membrane, whereas late apoptotic or necrotic cells, which have lost membrane integrity, exhibit red PI staining throughout the nucleus and a halo of green Annexin V-FITC staining on the cell surface. Each experiment contained three replicates and was repeated at least twice. The data are expressed as the mean $\pm \mathrm{SD}$.

Wound-healing assay. Cell migration was assessed using wound-healing assays. Cells were plated in a Costar 6-well plate (Corning Inc.) and the cell monolayer was scratched using a thin disposable p200 filtered pipette tip (Sangon Biotech Co., Ltd.). The initial gap length $(0 \mathrm{~h})$ and the residual gap length $24 \mathrm{~h}$ subsequent to wounding was analyzed from photomicrographs. The images were captured using an inverted microscope (TE200; Nikon Corp., Tokyo, Japan) Each experiment contained three replicates and was repeated at least twice. The data were presented as the mean \pm SD.

Cell invasion assay. Matrigel (BD Biosciences, Franklin Lakes, NJ, USA) was added into the upper chamber of a Transwell plate (Corning Inc., Corning, NY, USA) until it formed a thin gel layer. In total, $1 \times 10^{5} \mathrm{miR}-27 \mathrm{a}$-transfected $786-\mathrm{O}$ cells were inoculated into the upper compartment of the Transwell chambers, while $100 \mu \mathrm{l}$ /well of DMEM supplemented with $10 \%$ FCS was added to the lower chamber. Following incubation for $24 \mathrm{~h}$, the cells that did not penetrate the polycarbonate membrane at the bottom of the chamber were completely removed with a cotton swab. The migrated cells remaining on the bottom surface of the chamber were stained with $0.5 \%$ crystal violet (Beijing Solarbio Science \& Technology Co., Ltd., Beijing, China) for $3 \mathrm{~min}$, and then washed with PBS. The stained insert was washed thoroughly, dissolved with $33 \%$ acetic acid (Beijing Solarbio Science \& Technology Co., Ltd.) and the absorbance was measured at $595 \mathrm{~nm}$ with a microtiter plate reader. Each experiment contained three replicates and was repeated at least twice. The data were expressed as the mean \pm SD.

Western blot analysis. The miR-27a-transfected and miR-27a-mimic 780-O cells were washed with cold PBS and $300 \mu \mathrm{l}$ radioimmunoprecipitation buffer (Beyotime Institute of Biotechnology, Shanghai, China) was added to each group of cells. The cell lysates were agitated at $4^{\circ} \mathrm{C}$ for $30 \mathrm{~min}$ and centrifuged at $14,000 \mathrm{x} \mathrm{g}$ for $10 \mathrm{~min}$. Subsequently, the total protein concentrations in the supernatant were analyzed using a bicinchoninic acid protein assay kit (Thermo Fisher Scientific, Inc.) according to the manufacturer's protocol. For western blot analysis, $50 \mu \mathrm{g}$ proteins were separated by $12 \%$ [weight/volume $(\mathrm{w} / \mathrm{v})]$ sodium dodecylsulphate-polyacrylamide gel electrophoresis. The separated proteins were transferred onto a polyvinylidene fluoride (PVDF) membrane and were blocked with $5 \%(\mathrm{w} / \mathrm{v})$ skim milk in blocking buffer containing $10 \mathrm{mM}$ Tris-hydrochloric acid ( $\mathrm{pH}$ 7.6), $100 \mathrm{mM}$ sodium chloride and $0.1 \%$ (v/v) Tween 20 (all obtained from Sangon Biotech Co., Ltd.) for $2 \mathrm{~h}$ at room temperature. The following primary antibodies were added and incubated overnight on a shaker (SK-O/L180-E Analog Orbital Shaker \& Linear Shaker; Dragon Laboratory Instruments Ltd., Beijing, China) at $4^{\circ} \mathrm{C}$ : Rabbit 
A
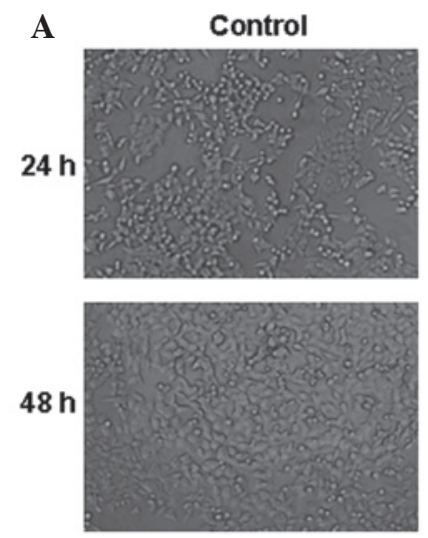

B
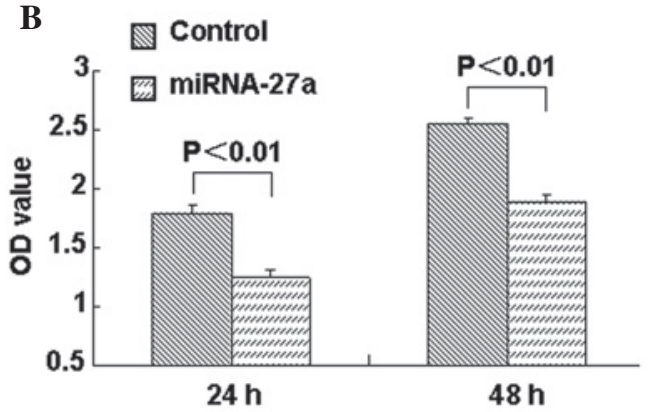

Figure 1. Effect of miRNA-27a transfection on RCC cell growth. (A) Growth of human RCC 786-O cells following miR-27a transfection. The 786-O cells were transfected with miRNA-27a for 24 and $48 \mathrm{~h}$ and were examined by an inverted microscope. (B) Methylthiazol tetrazolium assays were used to evaluate the proliferation ability of the 786-O cells. The data are expressed as the mean \pm standard deviation of 3 experiments, with 3 replicate wells for each transfection group. miRNA, microRNA; RCC, renal cell carcinoma; OD, optical density.

polyclonal anti-human epidermal growth factor receptor (EGFR; dilution, 1:500; catalog no., BS1101; Nanjing Bioworld Biotech Co., Ltd., Nanjing, Jiangsu, China), rabbit polyclonal anti-human cyclin D1 (dilution, 1:500; catalog no., BS2436; Nanjing Bioworld Biotech Co., Ltd), rabbit polyclonal antihuman cyclin-dependent kinase 2 (CDK2; dilution, 1:500; catalog no., 2546; Cell Signaling Technology, Inc., Danvers, MA, USA), rabbit polyclonal anti-human p27 (dilution, 1:500; catalog no., BS4143; Nanjing Bioworld Biotech Co., Ltd) and rabbit polyclonal anti-human $\beta$-actin (dilution, 1:500; catalog no., 4970; Cell Signaling Technology, Inc.). Subsequently, the PVDF membranes were incubated with secondary antibody (goat anti-rabbit immunoglobulin G; dilution, 1:2,000; catalog no., BS13278; Nanjing Bioworld Biotech Co., Ltd.) for $1 \mathrm{~h}$ at room temperature. The semi-quantification of proteins was evaluated using a Gel Imaging Analysis System (Tanon 2500R; Tanon Science and Technology, Co., Ltd., Shanghai, China). Each western blot analysis was repeated three times.

Mouse tumor xenograft model. All mice in the present study were kept under pathogen-free conditions and were maintained in accordance with the National Institutes of Health guidelines for the care and use of laboratory animals (32), with the approval of the Institutional Animal Care and Use Committee of the Jiangsu Provincial Academy of Chinese Medicine (Xuzhou, Jiangsu, SCXK 2010-0003). To evaluate the role of miR-27a in tumor formation, 12 nude BALB/c mice
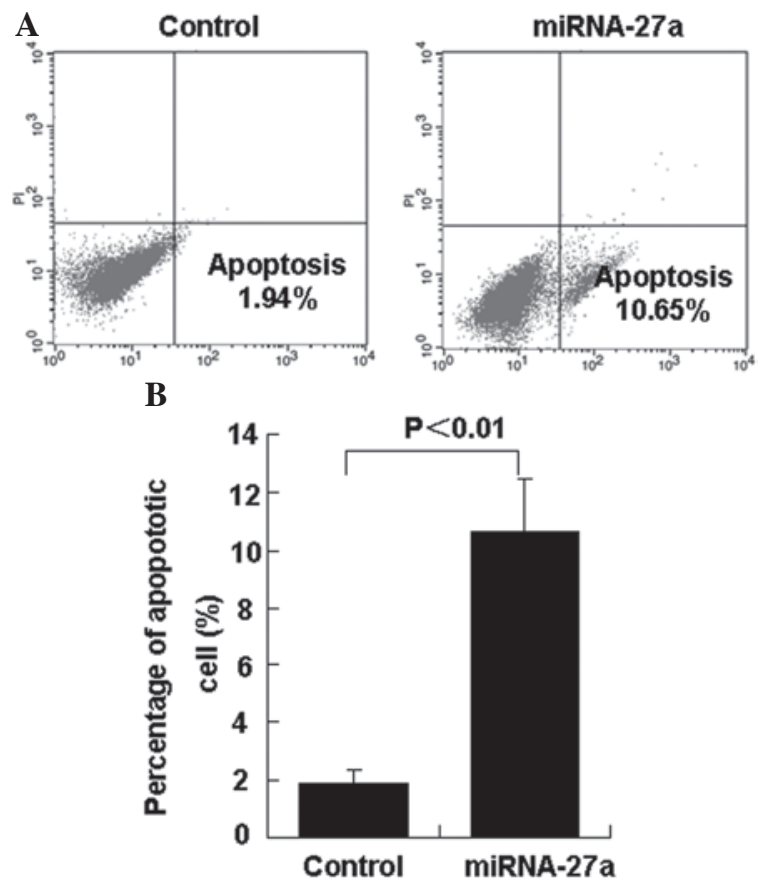

Figure 2. Effect of miRNA-27a transfection on the apoptosis of human renal cell carcinoma 786-O cells. (A) Apoptosis rate of the cells was examined by FCM. (B) Apoptosis rate analysis based on FCM. The data are expressed as the mean \pm standard deviation of 3 experiments, with 3 replicate wells for each transfection group. miRNA, microRNA; FCM, flow cytometry.

(between 5 and 6-weeks-old, purchased from Vital River Lab Animal Technology Co., Ltd., Beijing, China) were injected subcutaneously in the right flank with $3 \times 10^{6} 786-0$ cells. Once palpable tumors developed, the tumor volume was measured with a caliper every other day, using the following formula: Tumor volume $=\left(\right.$ length $\left.\mathrm{x} \mathrm{width}^{2}\right) / 2$. When the tumor volume reached an average volume of $100 \mathrm{~mm}^{3}$, the mice were randomly divided into a miR-27a group $(n=6)$ and a control group $(n=6)$. Mice in the miRNA-27a group were injected with miR-27a mimic, and the control group mice were injected with non-coding miR-27a mimic. miR-27a or miR-27a non-coding mimics were repeatedly administered by intratumoral injections every other day for 30 days.

Statistical analysis. Statistical analysis was performed using Student's $t$-test (SPSS software version 19; IBM SPSS, Armonk, NY, USA). $\mathrm{P}<0.05$ was considered to indicate a statistically significant difference.

\section{Results}

miR-27a transfection inhibits proliferation and induces apoptosis in human RCC 786-O cells. The present study examined the effect of miR-27a on RCC cell growth. As shown in Fig. 1A, the growth of miR-27a-transfected cells was decreased compared with the growth of the control group cells. MTT assays were performed at 24 and 48 h post-transfection, and it was found that the proliferation of 786-O cells was significantly suppressed at 24 and $48 \mathrm{~h}$ subsequent to miR-27a transfection compared with the control group (Fig. 1B). The present study investigated the effect of miR-27a on the percentage of apoptotic 786-O cells. In total, $24 \mathrm{~h}$ 


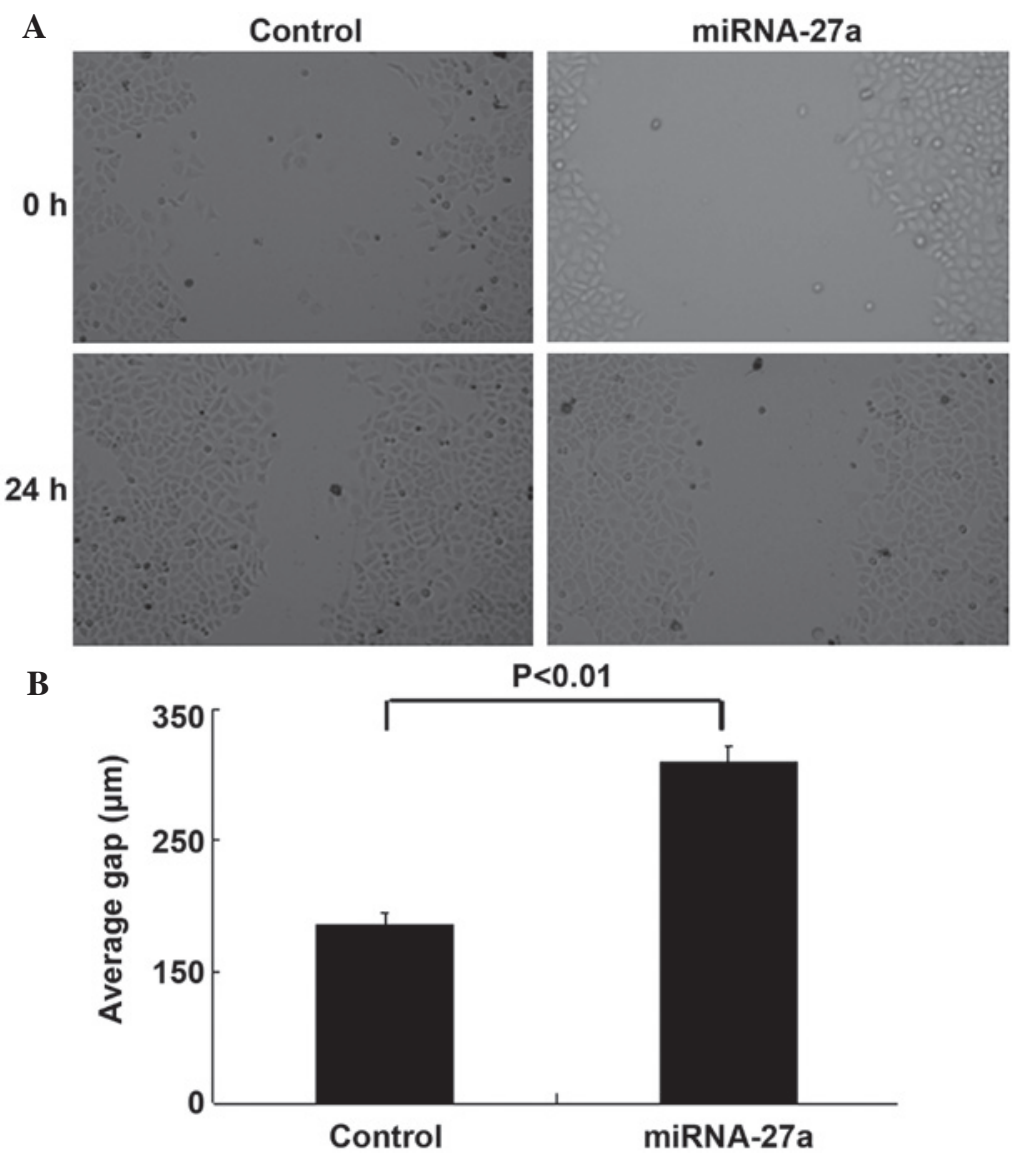

Figure 3. Effect of miRNA-27a on the migration of human renal cell carcinoma 786-O cells. (A) Cell migration abilities were determined using wound-healing assays. (B) The wound gaps were measured and the results were exhibited as the average wound gap. The data are expressed as the mean \pm standard deviation of 3 experiments, with 3 replicate wells for each transfection group. miRNA, microRNA.

subsequent to the transfection of miR-27a into 786-O cells, the percentage of apoptotic cells was significantly decreased in the miR-27a transfection group compared with the control group (Figs. 2A and B).

Overexpression of miR-27a blocks RCC cell migration and invasion. The wound-healing and Transwell invasion assays were performed to determine whether miR-27a was involved in the migratory and invasive behaviors of 786-O cells. The wound-healing assay demonstrated that inhibition of cell migration occurred in miR-27a transfectants compared with control transfectants (Figs. 3A and B). Transwell invasion assays demonstrated that the number of invading cells was significantly decreased in miR-27a-transfected cells compared with control group cells (Figs. 4A and B).

miR-27a attenuates RCC tumor growth in mouse xenograft models. The present data demonstrated that miR-27a exhibited antitumorigenic properties in RCC; therefore, the present study subsequently established a 786-O xenograft model to investigate the effect of miR-27a on tumorigenicity in vivo. As demonstrated by Fig. 5A, 15 days subsequent to the subcutaneous inoculation of 786-O cells, the mean tumor volume of the mice in the control and miR-27a treated group was $200 \mathrm{~mm}^{3}$. However, by day 30 , intratumoral delivery of miR-27a induced a notable inhibitory response to tumor growth compared with the control mice. In addition, the tumor weights were markedly decreased in the miR-27a-treated mice (Fig. 5B).

miR27a inhibits cell proliferation through EGFR-dependent cell cycle regulation. To additionally elucidate the molecular mechanism of the growth inhibition, the present study examined the expression of EGFR and other cell cycle proteins using western blot analysis. miR-27a reduced the expression of EGFR and its downstream gene cyclin D1, CDK2, and upregulated the expression of the CDK inhibitor p27 in 786-O cells (Figs. 6A). This suggests that miR-27a may suppress the growth of RCC cells by targeting the EGFR-dependent cell cycle signaling pathway.

\section{Discussion}

There are two crucial steps that enable cancer to progress: Uncontrolled cell proliferation and aggressive tumor cell metastasis (33). Numerous studies have implicated miRNAs as regulatory molecules involved in cell proliferation and metastasis of cancer in humans (34). Oncogenes and tumor suppressor genes are two groups of miRNAs that possess tumorigenesis functions (35). Numerous oncogenic miRNAs, including miR-21, miRNA-17-92 and miRNA-23b-3p, are involved in proliferative signaling, resisting growth suppression and apoptosis, cell immortality and triggering angiogenesis, invasion and metastasis of cells (36-38). Tumor 
A
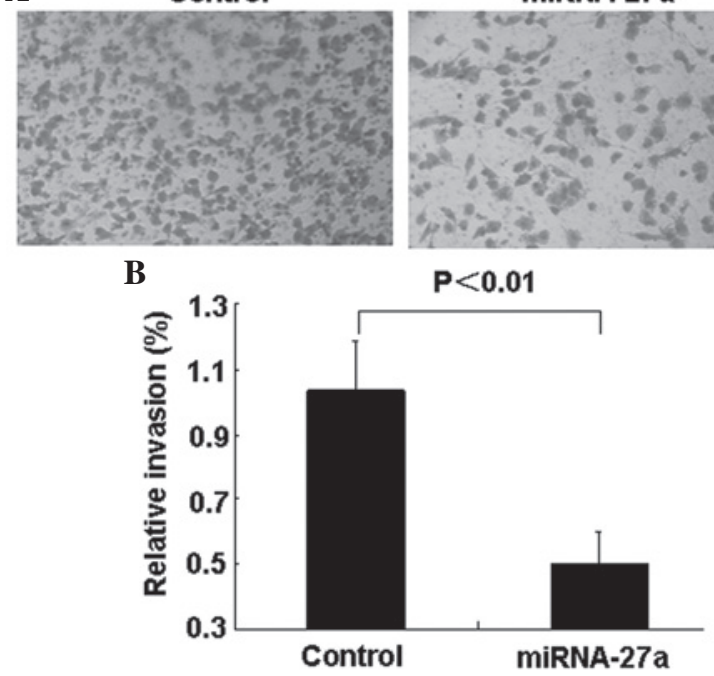

Figure 4. Effect of miRNA-27a on invasion of human renal cell carcinoma 786-O cells. (A) Invasion of 786-O cells was detected using Transwell chamber assays through a Matrigel basement membrane. (B) The results indicate the number of migrated cells. The data are expressed as the mean \pm standard deviation of 3 experiments, with 3 replicate wells for each transfection group. miRNA, microRNA.

A

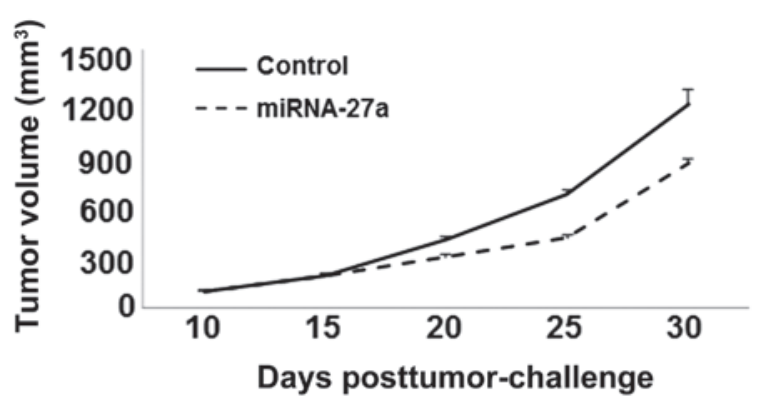

B

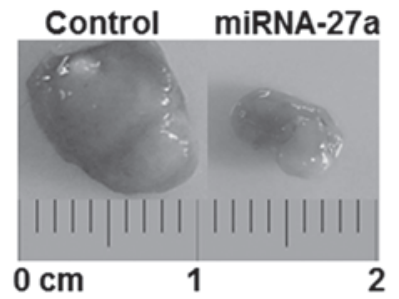

C

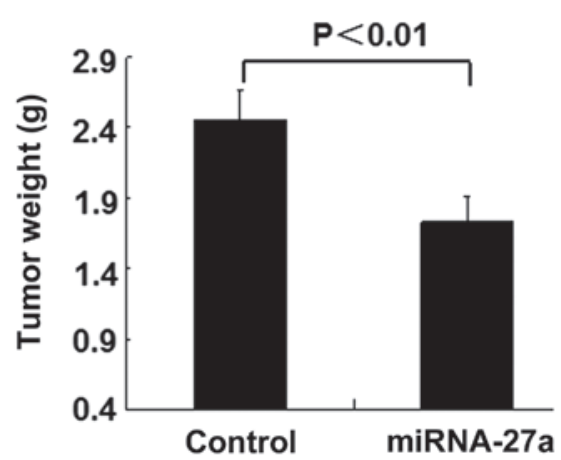

Figure 5. Effect of miRNA-27a on renal cell carcinoma tumor growth in vivo. (A) The tumor growth curve between day 0 and 30 following miRNA-27a injection. (B) Size of tumors. (C) Tumor weights of tumor xenografts in each group. miRNA, microRNA.

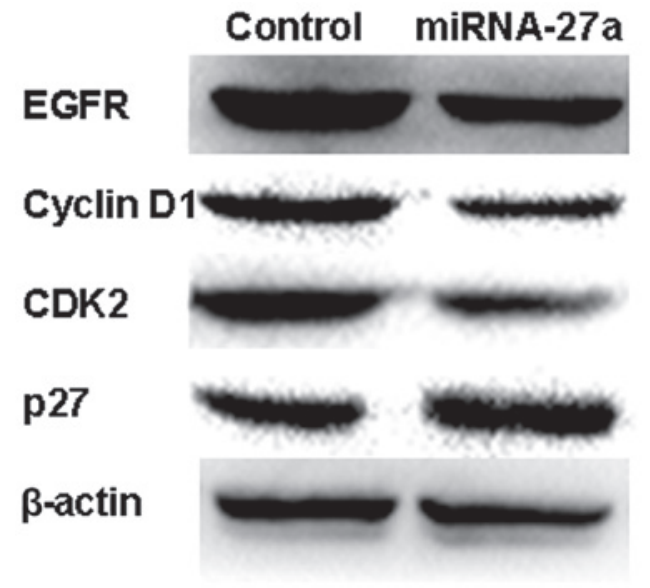

Figure 6. Analysis of EGFR and cell cycle protein expression in human renal cell carcinoma 786-O cells. (A) Western blotting analysis. The data are expressed as the mean \pm standard deviation of 3 experiments, with 3 replicates for each transfection group. miRNA, microRNA; EGFR, epidermal growth factor receptor; CDK, cyclin-dependent kinase.

suppressor miRNAs are involved in the reverse processes, including miRNA-1285 and miR-138, which have been demonstrated to be markedly decreased in RCC cells $(20,39)$. However, the effects of miR-27a on $\mathrm{RCC}$ have remain to be fully elucidated.

The present study demonstrated that miR-27a transfection suppressed cell growth, migration and invasion and induced cell apoptosis in human RCC 786-O cells in vitro. Furthermore, intratumoral delivery of miR-27a triggered regression of tumor growth in an RCC xenograft model in vivo. The present results suggest that miR-27a is a tumor suppressor and may be of therapeutic use in RCC. In addition, miR-27a was observed to become downregulated in several other tumor types, including colorectal cancer $(40,41)$, malignant melanoma (42), prostate cancer (43), oral squamous cell carcinoma (44) and acute promyelocytic leukemia (45), indicating that miR-27a is a possible tumor suppressor, which is consistent with the present results in RCC. However, miR-27a is regarded as an oncogene in several types of tumors. It has been reported that suppression of miR-27a inhibits gastric cancer cell growth by targeting prohibitin (29), and an additional study confirmed that the overexpression of miR-27 promotes metastasis of the human gastric cancer AGS cell line, and its depletion decreases metastasis (46). This inconsistency may be due to the various tumor types and cellular context. In the present study, restoration of miR-27a significantly inhibited cell migration and invasion, as demonstrated by a predication formed by bioinformatics and subsequent experimental demonstration.

The cell cycle is essential for maintaining balance between cell proliferation and cell death. Uncontrolled cell proliferation is a hallmark of cancer. Growth factors are critical in triggering signaling pathways, and stimulating cell cycle progression, which is critical for tumorigenesis (47). The EGFR family of tyrosine kinases is important in the etiology and progression of various carcinomas, including RCC $(48,49)$. EGFR demonstrates numerous oncogenic effects, including the initiation of DNA synthesis, regulation of the cell cycle, enhancement of cell growth and cell invasion and metastasis (50,51). In the present study, overexpression of EGFR was observed in the 
RCC cells. The increased expression of EGFR was associated with the deficiency of EGFR-targeting miRNA. A negative association was identified between the expression of EGFR and miR-27a in RCC tissues, confirming that EGFR may be a novel target of miR-27a. Furthermore, several cell cycle-associated proteins, including cyclin D1 and CDK 2, were observed to be downregulated following miR-27a overexpression, which resulted in the progression of the cell cycle. This may be attributed to the inhibition of the EGFR/protein kinase B/nuclear factor- $\mathrm{\kappa B} /$ cyclin D1 survival signaling pathway (52). Consequently, the inhibition of 786-O cell proliferation by miR-27a may be partly due to EGFR-dependent cell cycle regulation.

In summary, the present study demonstrated that miR-27a altered the cell proliferation, percentage of apoptotic cells and the migration and invasion of human RCC 786-O cells. Overexpression of miR-27a inhibited the EGFR signaling pathway in 786-O cells, which in turn regulated the cell cycle. The present results may aid in the understanding of the molecular function of miR-27a in RCC tumorigenesis and may provide novel diagnostic and therapeutic options for RCC.

\section{Acknowledgements}

The present study was supported by the Science and Technology Planned Projects of Xuzhou City (grant no. KC14SH099).

\section{References}

1. Jemal A, Siegel R, Ward E, Hao Y, Xu J, Murray T and Thun MJ: Cancer statistics, 2008. CA Cancer J Clin 58: 71-96, 2008.

2. Pascual D and Borque A: Epidemiology of kidney cancer. Adv Urol 2008: 782381, 2008

3. Koul H, Huh JS, Rove KO, Crompton L, Koul S, Meacham RB and Kim FJ: Molecular aspects of renal cell carcinoma: A review. Am J Cancer Res 1: 240-254, 2011.

4. Reeves DJ and Liu CY: Treatment of metastatic renal cell carcinoma. Cancer Chemother Pharmacol 64: 11-25, 2009.

5. Chow TF, Youssef YM, Lianidou E, Romaschin AD, Honey RJ, Stewart R, Pace KT and Yousef GM: Differential expression profiling of microRNAs and their potential involvement in renal cell carcinoma pathogenesis. Clin Biochem 43: 150-158, 2010.

6. Janzen NK, Kim HL, Figlin RA and Belldegrun AS: Surveillance after radical or partial nephrectomy for localized renal cell carcinoma and management of recurrent disease. Urol Clin North Am 30: 843-852, 2003.

7. Hadoux J, Vignot S and De La Motte Rouge T: Renal cell carcinoma: Focus on safety and efficacy of temsirolimus. Clin Med Insights Oncol 4: 143-154, 2010.

8. Rini BI, Campbell SC and Escudier B: Renal cell carcinoma. Lancet 373: 1119-1132, 2009.

9. Huang Y, Dai Y, Yang J, Chen T, Yin Y, Tang M, Hu C and Zhang L: Microarray analysis of microRNA expression in renal clear cell carcinoma. Eur J Surg Oncol 35: 1119-1123, 2009.

10. Naito S, Tomita Y, R ha SY, Uemura H, Oya M, Song HZ, Zhong LH and Wahid MI: Kidney Cancer Working Group report. Jpn J Clin Oncol 40 (Suppl 1): i51-i56, 2010.

11. Motzer RJ, Agarwal N, Beard C, Bhayani S, Bolger GB, Carducci MA, Chang SS, Choueiri TK, Hancock SL, Hudes GR, et al; National Comprehensive Cancer Network: Kidney cancer. J Natl Compr Canc Netw 9: 960-977, 2011.

12. Agarwala SS and Case S: Everolimus (RAD001) in the treatment of advanced renal cell carcinoma: A review. Oncologist 15: 236-245, 2010.

13. Filipowicz W, Bhattacharyya SN and Sonenberg N: Mechanisms of post-transcriptional regulation by microRNAs: Are the answers in sight? Nat Rev Genet 9: 102-114, 2008.

14. Schickel R, Boyerinas B, Park SM and Peter ME: MicroRNAs: Key players in the immune system, differentiation, tumorigenesis and cell death. Oncogene 27: 5959-5974, 2008.
15. Nelson KM and Weiss GJ: MicroRNAs and cancer: Past, present, and potential future. Mol Cancer Ther 7: 3655-3660, 2008.

16. Calin GA and Croce CM: MicroRNA signatures in human cancers. Nat Rev Cancer 6: 857-866, 2006.

17. White NM and Yousef GM: MicroRNAs: Exploring a new dimension in the pathogenesis of kidney cancer. BMC Med 8: 65, 2010.

18. Wiemer EA: The role of microRNAs in cancer: No small matter. Eur J Cancer 43: 1529-1544, 2007.

19. Esquela-Kerscher A and Slack FJ: Oncomirs - microRNAs with a role in cancer. Nat Rev Cancer 6: 259-269, 2006.

20. Yamasaki T, Seki N, Yamada Y, Yoshino H, Hidaka H, Chiyomaru T, Nohata N, Kinoshita T, Nakagawa M and Enokida H: Tumor suppressive microRNA 138 contributes to cell migration and invasion through its targeting of vimentin in renal cell carcinoma. Int J Oncol 41: 805-817, 2012.

21. Yamasaki T, Seki N, Yoshino H, Itesako T, Hidaka H, Yamada Y, Tatarano S, Yonezawa T, Kinoshita T, Nakagawa M and Enokida H: MicroRNA-218 inhibits cell migration and invasion in renal cell carcinoma through targeting caveolin- 2 involved in focal adhesion pathway. J Urol 190: 1059-1068, 2013.

22. Su B, Zhao W, Shi B, Zhang Z, Yu X, Xie F, Guo Z, Zhang X, Liu J, Shen Q, et al: Let-7d suppresses growth, metastasis, and tumor macrophage infiltration in renal cell carcinoma by targeting COL3A1 and CCL7. Mol Cancer 13: 206, 2014.

23. Chen X, Ruan A, Wang X, Han W, Wang R, Lou N, Ruan H, Qiu B, Yang $\mathrm{H}$ and Zhang X: miR-129-3p, as a diagnostic and prognostic biomarker for renal cell carcinoma, attenuates cell migration and invasion via downregulating multiple metastasis-related genes. J Cancer Res Clin Oncol 140: 1295-1304, 2014.

24. Wu D, Pan H, Zhou Y, Zhou J, Fan Y and Qu P: microRNA-133b downregulation and inhibition of cell proliferation, migration and invasion by targeting matrix metallopeptidase-9 in renal cell carcinoma. Mol Med Rep 9: 2491-2498, 2014.

25. Mertens-Talcott SU, Chintharlapalli S, Li X and Safe S: The oncogenic microRNA-27a targets genes that regulate specificity protein transcription factors and the G2-M checkpoint in MDA-MB-231 breast cancer cells. Cancer Res 67: 11001-11011, 2007.

26. Chintharlapalli S, Papineni S, Abdelrahim M, Abudayyeh A, Jutooru I, Chadalapaka G, Wu F, Mertens-Talcott S, Vanderlaag K, Cho SD, et al: Oncogenic microRNA-27a is a target for anticancer agent methyl 2-cyano-3,11-dioxo-18beta-olean-1,12-dien-30-oate in colon cancer cells. Int J Cancer 125: 1965-1974, 2009.

27. Vimalraj S, Miranda PJ, Ramyakrishna B and Selvamurugan N: Regulation of breast cancer and bone metastasis by microRNAs. Dis Markers 35: 369-387, 2013.

28. Jones KB, Salah Z, Del Mare S, Galasso M, Gaudio E, Nuovo GJ, Lovat F, LeBlanc K, Palatini J, Randall RL, et al: miRNA signatures associate with pathogenesis and progression of osteosarcoma. Cancer Res 72: 1865-1877, 2012.

29. Liu T, Tang H, Lang Y, Liu M and Li X: MicroRNA-27a functions as an oncogene in gastric adenocarcinoma by targeting prohibitin. Cancer Lett 273: 233-242, 2009.

30. Shi D, Li P, Ma L, Zhong D, Chu H, Yan F, Lv Q, Qin C, Wang W, Wang M, et al: A genetic variant in pre-miR-27a is associated with a reduced renal cell cancer risk in a Chinese population. PLoS One 7: e46566, 2012.

31. Reutelingsperger CP: Annexins: Key regulators of haemostasis, thrombosis, and apoptosis. Thromb Haemost 86:413-419, 2001

32. National Research Council: Guide for the Care and Use of Laboratory Animals. 8th edition. National Academies Press, Washington, DC, 2011.

33. Yan K, Gao J, Yang T, Ma Q, Qiu X,Fan Q and Ma B: MicroRNA-34a inhibits the proliferation and metastasis of osteosarcoma cells both in vitro and in vivo. PLoS One 7(3):e33778, 2012.

34. Deng S, Calin GA, Croce CM, Coukos G and Zhang L: Mechanisms of microRNA deregulation in human cancer. Cell Cycle 7: 2643-2646, 2008.

35. Zhang B, Pan X, Cobb GP and Anderson TA: microRNAs as oncogenes and tumor suppressors. Dev Biol 302: 1-12, 2007.

36. Li X, Xin S, He Z, Che X, Wang J, Xiao X, Chen J and Song X: MicroRNA-21 (miR-21) post-transcriptionally downregulates tumor suppressor PDCD4 and promotes cell transformation, proliferation, and metastasis in renal cell carcinoma. Cell Physiol Biochem 33: 1631-1642, 2014.

37. Chow TF, Mankaruos M, Scorilas A, Youssef Y, Girgis A, Mossad S, Metias S, Rofael Y, Honey RJ, Stewart R, et al: The miR-17-92 cluster is over expressed in and has an oncogenic effect on renal cell carcinoma. J Urol 183: 743-751, 2010. 
38. Zaman MS, Thamminana S, Shahryari V, Chiyomaru T, Deng G, Saini S, Majid S, Fukuhara S, Chang I, Arora S, et al: Inhibition of PTEN gene expression by oncogenic miR-23b-3p in renal cancer. PLoS One 7: e50203, 2012.

39. Hidaka H, Seki N, Yoshino H, Yamasaki T, Yamada Y, Nohata N, Fuse M, Nakagawa $\mathrm{M}$ and Enokida $\mathrm{H}$ : Tumor suppressive microRNA-1285 regulates novel molecular targets: Aberrant expression and functional significance in renal cell carcinoma. Oncotarget 3: 44-57, 2012.

40. Xi Y, Shalgi R, Fodstad O, Pilpel Y and Ju J: Differentially regulated micro-RNAs and actively translated messenger RNA transcripts by tumor suppressor p53 in colon cancer. Clin Cancer Res 12: 2014-2024, 2006.

41. Volinia S, Calin GA, Liu CG, Ambs S, Cimmino A, Petrocca F, Visone R, Iorio M, Roldo C, Ferracin M, et al: A microRNA expression signature of human solid tumors defines cancer gene targets. Proc Natl Acad Sci USA 103: 2257-2261, 2006.

42. Dai Y, Sui W, Lan H, Yan Q, Huang H and Huang Y: Comprehensive analysis of microRNA expression patterns in renal biopsies of lupus nephritis patients. Rheumatol Int 29: 749-754, 2009.

43. Fletcher CE, Dart DA, Sita-Lumsden A, Cheng H, Rennie PS and Bevan CL: Androgen-regulated processing of the oncomir miR-27a, which targets Prohibitin in prostate cancer. Hum Mol Genet 21: 3112-3127, 2012

44. Kozaki K, Imoto I, Mogi S, Omura K and Inazawa J: Exploration of tumor-suppressive microRNAs silenced by DNA hypermethylation in oral cancer. Cancer Res 68: 2094-2105, 2008.

45. Saumet A, Vetter G, Bouttier M, Portales-Casamar E, Wasserman WW, Maurin T, Mari B, Barbry P, Vallar L, Friederich E, et al: Transcriptional repression of microRNA genes by PML-RARA increases expression of key cancer proteins in acute promyelocytic leukemia. Blood 113: 412-421, 2009.
46. Zhang Z, Liu S, Shi R and Zhao G: miR-27 promotes human gastric cancer cell metastasis by inducing epithelial-to-mesenchymal transition. Cancer Genet 204: 486-491, 2011.

47. Tomas A, Futter CE and Eden ER: EGF receptor trafficking: Consequences for signaling and cancer. Trends Cell Biol 24: 26-34, 2014.

48. Stumm G, Eberwein S, Rostock-Wolf S, Stein H, Pomer S, Schlegel J and Waldherr R: Concomitant overexpression of the EGFR and erbB-2 genes in renal cell carcinoma (RCC) is correlated with dedifferentiation and metastasis. Int J Cancer 69: 17-22, 1996.

49. Dias F, Teixeira AL, Santos JI, Gomes M, Nogueira A, Assis J and Medeiros R: Renal cell carcinoma development and miRNAs: A possible link to the EGFR pathway. Pharmacogenomics 14: 1793-1803, 2013.

50. Shelton JG, Steelman LS, Abrams SL, White ER, Akula SM, Franklin RA, Bertrand FE, McMahon M and McCubrey JA: Conditional EGFR promotes cell cycle progression and prevention of apoptosis in the absence of autocrine cytokines. Cell Cycle 4: 822-830, 2005.

51. Lui VW and Grandis JR: EGFR-mediated cell cycle regulation. Anticancer Res 22 (1A): 1-11, 2002.

52. Liu W, Yin T, Ren J, Li L, Xiao Z, Chen X and Xie D: Activation of the EGFR/Akt/NF- $\mathrm{B}$ /cyclinD1 survival signaling pathway in human cholesteatoma epithelium. Eur Arch Otorhinolaryngol 271: 265-273, 2014. 